\title{
Asthma impacts on workplace productivity in employed patients who are symptomatic despite background therapy: a multinational survey
}

This article was published in the following Dove Press journal:

Journal of Asthma and Allergy

\author{
Kevin Gruffydd-Jones' \\ Mike Thomas ${ }^{2}$ \\ Miguel Roman-Rodríguez ${ }^{3}$ \\ Antonio Infantino ${ }^{4}$ \\ J Mark FitzGerald ${ }^{5}$ \\ lan Pavord ${ }^{6}$ \\ Jennifer $\mathrm{M} \mathrm{Haddon}^{7}$ \\ Ulrich Elsasser ${ }^{8}$ \\ Christian Vogelberg ${ }^{9}$ \\ 'Box Surgery, Box, Wiltshire, UK; \\ ${ }^{2}$ Primary Care and Population Sciences, \\ University of Southampton, \\ Southampton, UK; ${ }^{3}$ Son Pisà Primary \\ Health Care Centre, Balearic Health \\ Centre, Palma de Mallorca, Spain; \\ ${ }^{4}$ Società Italiana Interdisciplinare per le \\ Cure Primarie (SIICP), Bari, Italy; \\ ${ }^{5}$ Institute for Heart and Lung Health, \\ University of British Columbia, \\ Vancouver, British Columbia, Canada; \\ ${ }^{6}$ Respiratory Medicine Unit and Oxford \\ Respiratory NIHR Biomedical Research \\ Centre, Nuffield Department of \\ Medicine, University of Oxford, Oxford, \\ UK; ${ }^{7}$ TA Dig Excellence + Healthcare \\ Inno Med, Boehringer Ingelheim \\ International $\mathrm{GmbH}$, Ingelheim am Rhein, \\ Germany; ${ }^{8}$ Biostatistics and Data \\ Sciences, Boehringer Ingelheim Pharma \\ $\mathrm{GmbH} \&$ Co. KG, Biberach an der Riss, \\ Germany; ${ }^{9}$ Department of Pediatric \\ Pneumology and Allergology, University \\ Hospital Carl Gustav Carus, Technical \\ University of Dresden, Dresden, \\ Germany
}

Correspondence: Kevin Gruffydd-Jones

Box Surgery, London Road, Box,

Wiltshire SNI 3 8NA, UK

Tel +44 I22 5744195

Fax +44 I22 5742646

Email k.gruffydd-jones@nhs.net
Background: Asthma affects millions of people worldwide, with many patients experiencing symptoms that affect their daily lives despite receiving long-term controller medication. Purpose: Work is a large part of most people's lives, hence this study investigated the impact of uncontrolled asthma on work productivity in adults receiving asthma maintenance therapy.

Patients and methods: An online survey was completed by employed adults in Brazil, Canada, Germany, Japan, Spain and the UK. Participants were confirmed as symptomatic using questions from the Royal College of Physicians' 3 Questions for Asthma tool. The survey contained the Work Productivity and Activity Impairment - Specific Health Problem questionnaire and an open-ended question on the effect of asthma at work.

Results: Of the 2,055 patients on long-term maintenance therapy screened, 1,598 were symptomatic and completed the survey. The average percentage of work hours missed in a single week due to asthma symptoms was $9.3 \%$, ranging from $3.5 \%$ (UK) to $17.4 \%$ (Brazil). Nearly three-quarters of patients reported an impact on their productivity at work caused by asthma. Overall work productivity loss (both time off and productivity whilst at work) due to asthma was $36 \%$, ranging from $21 \%$ (UK) to $59 \%$ (Brazil). When asked how asthma made participants feel at work, many respondents highlighted how their respiratory symptoms affect them. Tiredness, weakness and mental strain were also identified as particular challenges, with respondents describing concerns about the perception of colleagues and feelings of inferiority.

Conclusions: This study emphasizes the extent to which work time is adversely affected by asthma in patients despite the use of long-term maintenance medication, and provides unique personal insights. Strategies to improve patients' lives may include asthma education, optimizing asthma management plans and running workplace well-being programs. Clinicians, employers and occupational health teams should be more aware of the impact of asthma symptoms on employees, and work together to help overcome these challenges.

Keywords: work productivity, asthma, burden, costs

\section{Plain language summary}

Asthma can make daily life difficult for millions of people worldwide. We surveyed people who have asthma to find out how it affects their work lives. These people had asthma symptoms despite taking long-term treatment. Over 1,500 people in Brazil, Canada, Germany, Japan, Spain and the UK completed an online survey. This survey showed that workers missed nearly one-tenth of their weekly work due to their asthma. Three out of four workers felt they could not work to their full potential because of their illness. Asthma 
reduced work productivity by more than a third. Personal insights showed the impact of asthma on their emotional well-being at work, including tiredness, weakness and mental strain. Study participants also described feelings of desperation, stress, embarrassment, helplessness and guilt. It shows how much poorly treated asthma symptoms can impact society. We encourage both healthcare workers and workplaces to act together to improve the lives of people with asthma.

\section{Introduction}

Globally, asthma is the most prevalent chronic respiratory disease, with recent estimates showing it directly affects over 358 million individuals. ${ }^{1}$ In spite of the development of effective treatments and new management paradigms, asthma continues to have a huge impact on patients' lives, with over $45 \%$ of patients with asthma estimated as having poorly controlled disease. ${ }^{2,3}$ International trends have shown that during the period 2006-2012 there was no significant reduction in global asthma mortality rates, which remained at 0.19 deaths per 100,000 people. $^{4}$ Further to this, asthma causes a burden in terms of impaired quality of life and physical, psychological and social disability, with estimates that asthma accounts for $1 \%$ of disability-adjusted life-years lost worldwide. ${ }^{5,6}$

Poorly controlled asthma is associated with reduced work productivity versus well-controlled asthma. ${ }^{7-9}$ In a European study, 24-59\% of surveyed patients with asthma reported at least 1 day of absence from work or education in the previous year. ${ }^{7}$ In a US study, workers with poorly controlled asthma (39.7\% of respondents) had greater work and activity impairment versus those with well-controlled asthma. ${ }^{8}$ These findings were also echoed in a recent prospective study in Canada assessing work-related asthma, which looked at two aspects involved in productivity loss: presenteeism (which represents the impact on productivity whilst working) and absenteeism (which only represents time taken off work). In the study, people with uncontrolled asthma had greater productivity loss compared with those with controlled asthma, and the productivity loss due to presenteeism was greater than loss due to absenteeism. ${ }^{10}$ Another study in Canada showed that optimizing asthma control improved presenteeism to a greater extent than absenteeism, and therefore presenteeism represents an important preventable burden. ${ }^{11}$ In an Australian study, improving asthma control was again found to be an important target for optimizing workplace productivity, with presenteeism and impairment in daily activity more frequently reported in severe versus non-severe asthma. $^{12}$ This highlights the importance of evaluating presenteeism when considering productivity loss and the overall economic burden of asthma.

There is a substantial economic burden of time lost at work due to asthma. This impact on work productivity is not only on the individual (in terms of sick pay/hours lost and their well-being), but also affects colleagues, employers and society as a whole. ${ }^{13-15}$ A study in Spain reported that indirect costs were significantly higher in the $57.6 \%$ of patients with poorly controlled asthma compared with patients whose disease was controlled. ${ }^{9}$ The cost of caretakers of dependents with asthma taking time off work contributes a large proportion of the indirect costs associated with asthma. ${ }^{15}$ Poor asthma control in children also impacts the quality of life and productivity of caregivers. ${ }^{16}$ Reports from around the world have shown that the detrimental effects of inadequately controlled asthma start in childhood and impact both school productivity and attendance. ${ }^{17-19}$

A key part of this current study is that it recruited patients already treated with controller medication, and investigated the persisting impact of asthma on a patient's ability to work. The study also measured a patient's ability to work to their full potential, which can often be overlooked in the assessment of asthma, when attention can be on other daily activities. The findings of this current study should enhance our understanding of the burden of asthma across continents.

This is the first transcontinental survey that we are aware of that aimed to assess quantitative measures of work productivity and collected personal insights from adults with symptomatic asthma who receive long-term controller medication.

\section{Methods}

\section{Study design}

The survey was designed to collect both quantitative and qualitative data on the effect of asthma at work in individuals with asthma that were poorly controlled despite receiving long-term asthma maintenance therapy. The survey was carried out between April-September 2015 by Research Now ${ }^{\circledR}$ (London, UK). Participants were recruited from six countries: Brazil, Canada, Germany, Japan, Spain and the UK. A random sample of approximately 60,000 individuals from the online consumer panel of Research Now ${ }^{\circledR}$ who had previously been profiled as adult asthma sufferers in employment were invited via email to participate in this survey on the topic of "healthcare" (Figure 1). One exception to this was Japan, where the consumer panel had not previously 


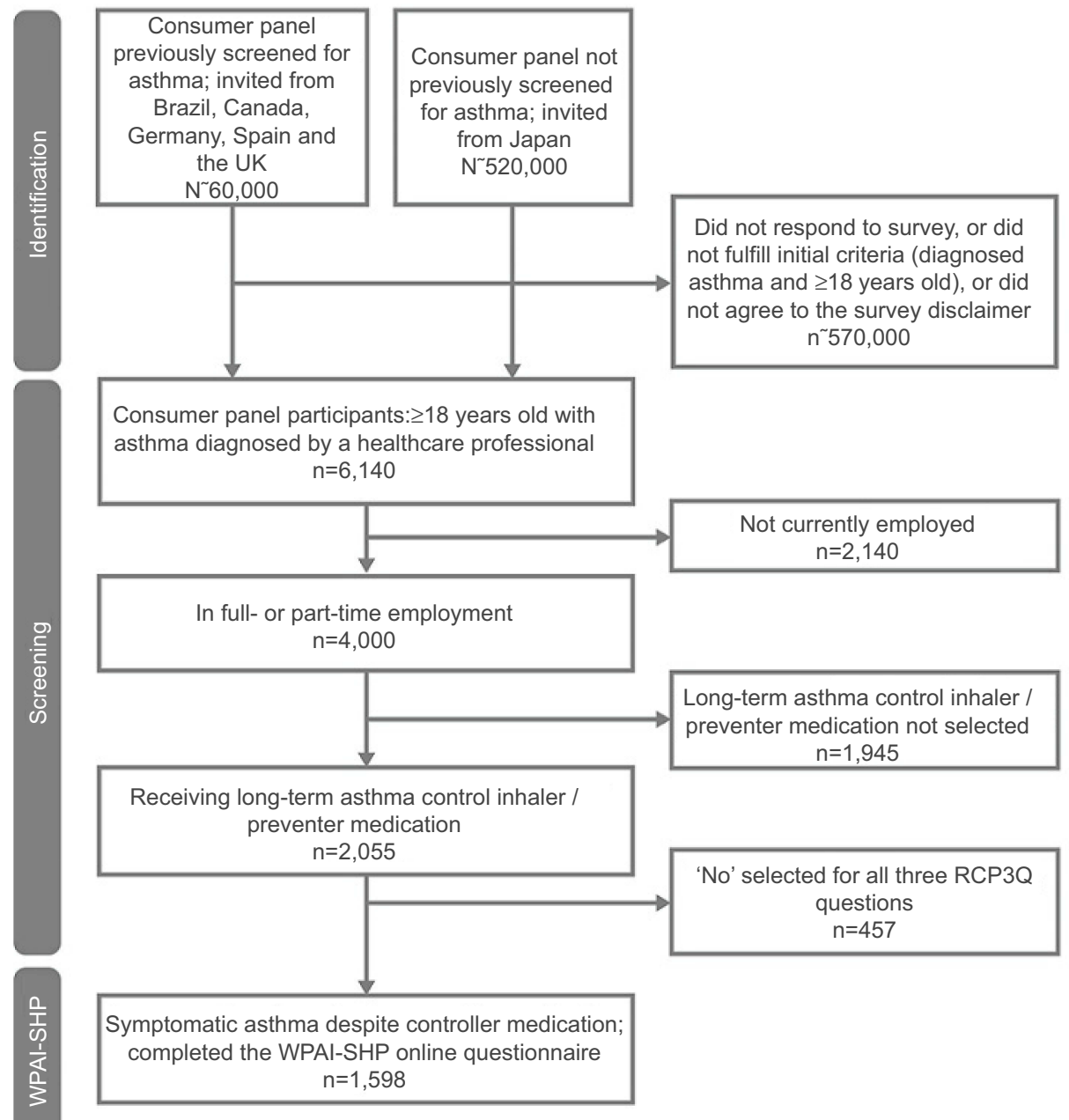

Figure I Participant selection. The initial part of the survey included screening questions to ensure eligible participation. This included patients who were: over 18 years old; had asthma diagnosed by a healthcare professional; were in employment; were on long-term asthma control; and who had asthma that affected their sleep/daytime or usual activity in the previous month (see supplementary materials).

Abbreviations: RCP3Q, Royal College of Physicians' 3 Questions for Asthma; WPAI-SHP, Work Productivity and Activity Impairment - Specific Health Problem.

been screened for asthma or employment. For Japan, approximately 520,000 people were initially invited, with approximately 50,000 responding and being screened for eligibility. The questionnaire was translated for each country.

The 6,140 eligible individuals from the six countries who responded to the invitation, who were confirmed as being over 18 years old and as having asthma diagnosed by a healthcare professional, were then further screened for eligibility, which included being in employment and being symptomatic despite receiving a long-term asthma controller medication (Figure 1; screener questions are detailed in the supplementary materials section). The survey respondents provided their consent to participate in the survey online before answering any of the screening questions, and all data were anonymized. All eligible patients were then asked to complete the online survey containing the Work Productivity and Activity Impairment - Specific Health Problem (WPAI-SHP) questionnaire to describe how asthma had impacted their lives in the previous week, and to answer an additional open-ended question: "How does your asthma at work make you feel?" (see supplementary materials).

The survey was conducted to conform with Market Research Society regulations, and the codes of conduct of the Market Research Society, British Healthcare Business Intelligence Association and European Pharmaceutical Market Research Association. Therefore, ethics approval was not sought. Respondents provided consent to participate in the survey by selecting a yes/no option before entering the screening questionnaire. 
As is common practice to reduce non-response bias, the survey was short (taking approximately 5 mins), each participant was offered a nominal incentive (ie, a small honorarium) for completing the survey, and reminders were sent to all participants. Each country had a quota for the overall number of respondents, which was nationally representative of the population size.

\section{Participants}

The survey participants were adults (aged $\geq 18$ years) with asthma diagnosed by a healthcare professional. They were in either full- or part-time employment, and were currently receiving treatment with long-term asthma maintenance with or without reliever therapy. During screening, survey participants were confirmed as symptomatic using questions from the Royal College of Physicians' 3 Questions for Asthma morbidity scoring tool, which provided an indication of poor asthma control (see supplementary materials) ${ }^{20,21}$ If a participant answered "yes" to any of the three questions (ie, a score of $\geq 1$ ), they were identified as having poor asthma control and were then directed immediately to the WPAI-SHP section of the questionnaire.

\section{Work Productivity and Activity Impairment - Specific Health Problem Questionnaire}

The WPAI-SHP questionnaire is a validated tool that quantifies the extent of work loss and impairment due to poor health, as well as the symptom or problem specified. ${ }^{22}$ The questionnaire is a patient-reported quantitative assessment of the amount of impairment during the previous 7 days (see supplementary materials). Version 2.0 of this questionnaire was used, which repeats instructions directly above the scales for questions 5 and 6 to improve the accuracy of response. ${ }^{23}$ To briefly summarize, this questionnaire examines absenteeism (work time missed due to asthma), presenteeism (how asthma impairs productivity during working), total work productivity loss (a combination of absenteeism and presenteeism) and activity impairment in daily activities other than work. ${ }^{24}$

\section{Statistical analysis}

Descriptive statistics were used to summarize the quantitative data collected in this survey. The questions of the WPAI-SHP cover the following: Q1, employment status; Q2, number of hours missed due to asthma; Q3, number of hours missed due to other reasons; $\mathrm{Q} 4$, total number of hours worked; Q5, the degree to which asthma impairs productivity whilst working; and Q6, the degree to which asthma impairs regular daily activities. ${ }^{23}$ Absenteeism is expressed as the percentage of the working time of the week missed due to asthma (Q2/[Q2+Q4]x100). Both the impact on work productivity and regular daily activities were reported by the patient on a scale of $0-10$; this was then categorized as follows: 0 , no effect; $1-3$, small effect; 4-7, medium effect; and 8-10, large effect. A prominent impairment in this study was considered as a score of $>4$. Total work productivity loss is calculated using the following equation from the standard WPAI-SHP questionnaire: $\mathrm{Q} 2 /(\mathrm{Q} 2+\mathrm{Q} 4)+([1-(\mathrm{Q} 2 /[\mathrm{Q} 2+\mathrm{Q} 4])] \times[\mathrm{Q} 5 / 10])$. This calculation takes into consideration the amount of time lost (absenteeism) and the degree of impairment affected whilst also working to produce an overall percentage that summarizes the work impairment due to asthma.

In addition, the two endpoints 'Overall impairments due to asthma' and 'Total work productivity loss' were analyzed by analysis of variance (ANOVA), with country and chronic obstructive pulmonary disease (COPD), and country and age, as factors. Two ANOVA models were applied, including and excluding the interaction.

\section{Qualitative data}

All participants who completed the survey were also asked an open-ended question: Q7 "How does your asthma at work make you feel?" To allow common themes to be identified from this qualitative section, all the verbatim answers were converted into descriptors as part of a code frame created specifically for this project; these descriptors were then arranged into categories. For example, participants used various ways to describe their respiratory impairment by using words such as "suffocated", "dyspnea/shortage of breath" or "chest pain"; these words then became descriptors that were then included in the category "Respiratory symptoms". A further example is the use of words such as "isolated", "self-conscious" and "stressed", which were provided by participants to describe their feelings when their asthma affected them in the workplace; these became descriptors that were then included in the category "Mentally strained". Each individual's response to the open question could identify difficulties that belonged in more than one category (ie, a survey participant could describe themselves both as having respiratory symptoms and being mentally strained). A list of the common descriptors based on responses from $\geq 3$ study participants is found in Table S1. 


\section{Results}

\section{Patient characteristics}

Of the 2,055 survey respondents screened that were in employment and receiving a long-term asthma control inhaler and/or preventer medication, 457 were asymptomatic; the remaining 1,598 were classed as symptomatic (Figure 1). Patient characteristics are summarized in Table 1. A wide age range was sampled, with nearly half of respondents aged over 40 years. Three-quarters of patients were in full-time employment. Of the comorbidities included in the questionnaire, high blood pressure and high cholesterol were common comorbidities, each affecting approximately $20 \%$ of survey participants.

\section{WPAI-SHP results}

In total, 1,598 symptomatic participants completed the online WPAI-SHP questionnaire. Due to asthma, 9.3\% of the working week was missed, with a range of $3.5 \%$ in the UK to $17.4 \%$ in Brazil (Figure 2). Amongst both full- and part-time workers, this averaged to $3.4 \mathrm{hrs}$ in 1 week.

\section{Table I Survey participant characteristics}

\begin{tabular}{|l|l|}
\hline Characteristic & Total, n (\%) \\
\hline Asthma diagnosed by a HCP & $1,598(100)$ \\
\hline Age, years & \\
I8-24 & $146(9.1)$ \\
$25-39$ & $687(43.0)$ \\
$40-59$ & $634(39.7)$ \\
$\geq 60$ & $131(8.2)$ \\
\hline Country & \\
Brazil & $200(12.5)$ \\
Canada & $200(12.5)$ \\
Germany & $293(18.3)$ \\
Japan & $305(19.1)$ \\
Spain & $300(18.8)$ \\
UK & $300(18.8)$ \\
\hline Employment status & \\
Full-time & $1,213(75.9)$ \\
Part-time & $385(24.1)$ \\
\hline Comorbidities & \\
High blood pressure & $344(21.5)$ \\
High cholesterol & $311(19.5)$ \\
Type 2 diabetes & $165(10.3)$ \\
Arthritis & $262(16.4)$ \\
COPD & $127(7.9)$ \\
Osteoporosis & $86(5.4)$ \\
\hline
\end{tabular}

Abbreviations: COPD, chronic obstructive pulmonary disease; $\mathrm{HCP}$, healthcare professional.
In terms of presenteeism, $74 \%$ of participants reported a reduction in productivity at work caused by asthma (score $1-10$ ), with $42 \%$ reporting a prominent reduction (score $\geq 4 / 10$; Figure 3 ). Overall work productivity loss (a figure that combines both absenteeism and presenteeism) due to asthma was $36 \%$; this ranged from $21 \%$ in the UK to $59 \%$ in Brazil (Figure S1). Further to this, asthma affected $83 \%$ of respondents' ability to perform regular daily activities (score $1-10$ ), with $51 \%$ reporting a prominent impairment (score $\geq 4 / 10$ ) (Figure 4).

When results were analyzed by COPD and age, patients with COPD were found to have a higher mean overall impairment and total work productivity loss than non-COPD patients. Mean overall impairment and total work productivity loss both decreased for patients aged $\geq 40$ years. There was no significant interaction between COPD and country or between age and country. See supplementary materials (Table S2) for more details.

\section{Work productivity: patient insights}

When asked how asthma made participants feel at work, the most commonly cited challenge was how respiratory symptoms directly affected them in the workplace (Figure 5). Tiredness/weakness, mental strain and physical impairments were all noteworthy challenges (Figure 5). A further factor was a negative perception from colleagues due to their asthma symptoms, which was most notable in Japan and the UK (Figure S2).

Overall, when asked how asthma makes them feel, over two-thirds of respondents indicated that asthma had a negative impact on their work activities.

Selected statements from patients further illustrate this:

[Asthma at work] can make me feel quite self-conscious if I start coughing or wheezing. I feel guilty if I need to take a break and take my inhaler.

Sad, depressed and as if I can't do a lot.

[I] fatigue easily, [and have] difficulty in concentrating.

Perceptions of colleagues were also a common concern:

[E]mbarrassed, as I don't like using my inhalers in front of people.

[G]uilty, as colleagues sometimes cover for me.

Feelings of frustration were often coupled with the physical impairments: 


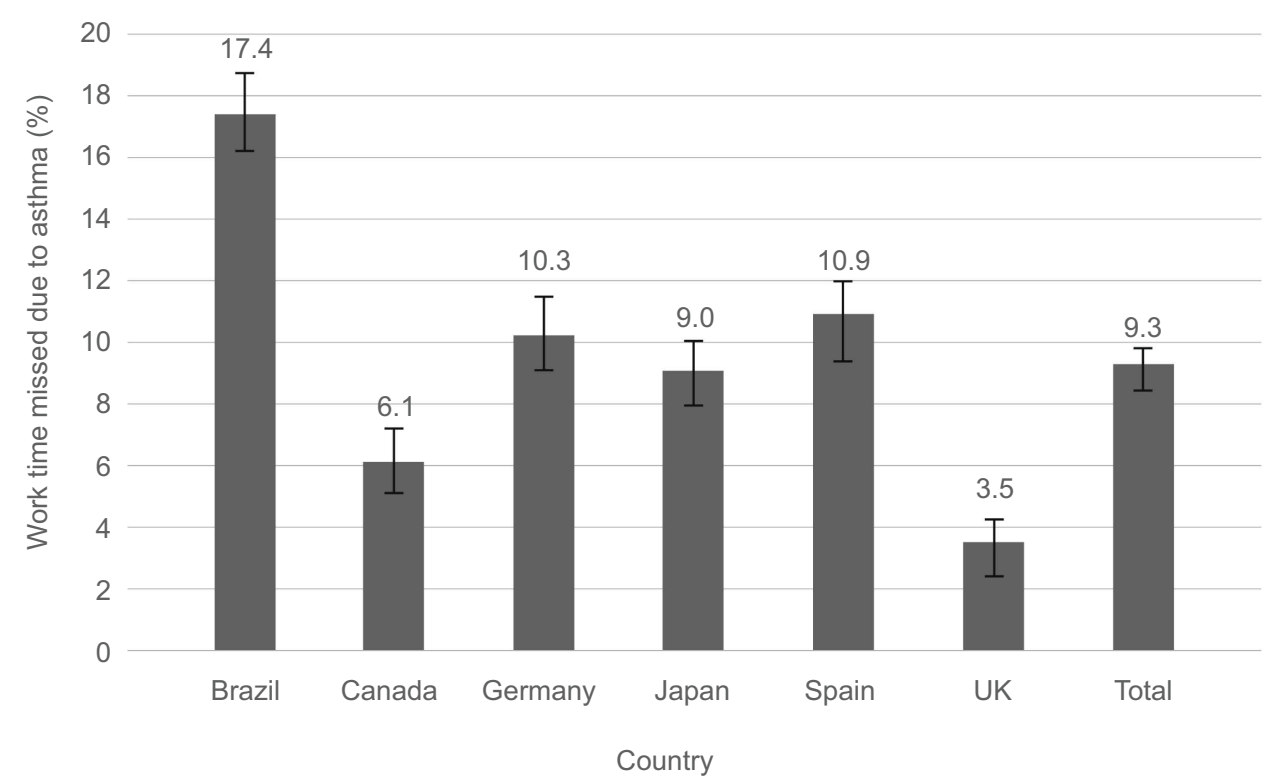

Figure 2 Absenteeism (percentage of hours missed per week due to asthma) by country. Absenteeism captures the percentage of hours missed from work because of asthma, including hours missed on sick days and time missed from being late or leaving early due to asthma. All respondents $(N=1,559)$; Brazil $(n=198)$; Canada $(n=189)$; Germany ( $n=289)$; Japan $(n=301)$; Spain $(n=297)$; UK $(n=285)$. Error bars represent standard error of the mean.

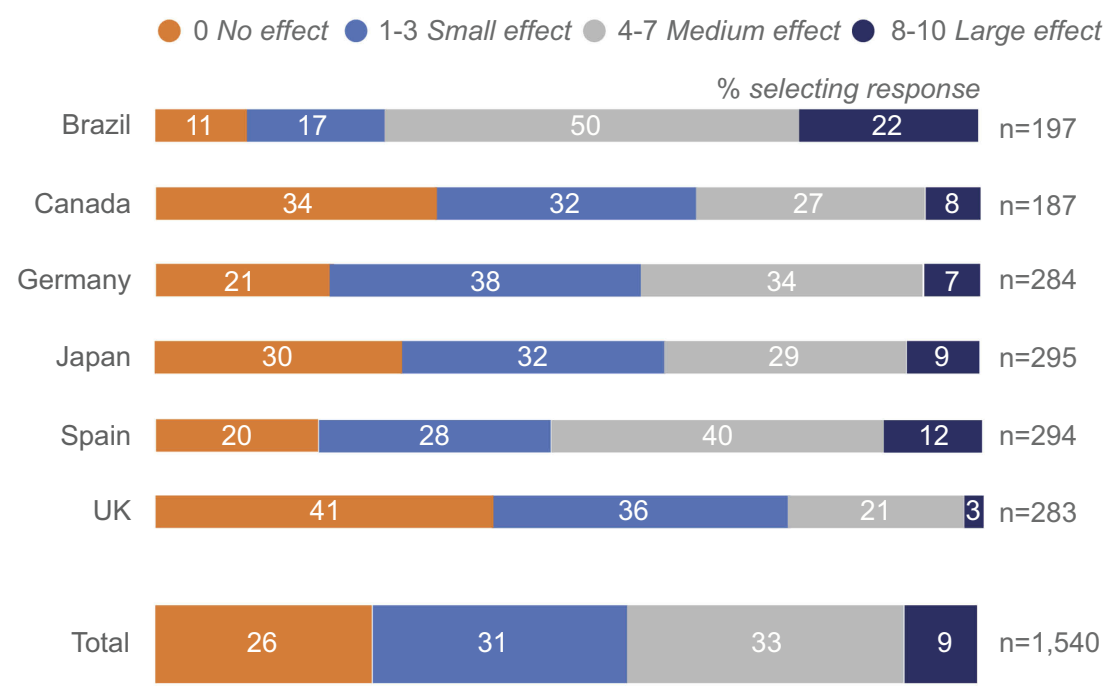

Figure 3 Impact of asthma on productivity at work. WPAI-SHP Q5: "During the past seven days, how much did asthma affect your productivity while you were working?" Answered on a $0-10$ score, with $0=$ asthma had no effect on my work and $10=$ asthma completely prevented me from working.

Abbreviation: WPAI-SHP, Work Productivity and Activity Impairment - Specific Health Problem.

[F]rustrated at being short of breath and sometimes embarrassed.

[D]ifficult to communicate with people as breathless.

[L]ess able to walk around quickly/take the stairs.

A number of respondents also felt inferior and disadvantaged:

$[\mathrm{M}]$ akes me feel like a big failure.

[M]akes me feel useless.
Regarding their working conditions, one person commented:

I can usually manage my asthma symptoms at work; however, last week the building was undergoing construction work and there was a lot of dust around. I've had severe asthma symptoms and a chest infection for 7 days now due to this. This made me feel upset, as my working conditions were not appropriate for me and this was not considered by my employer. 


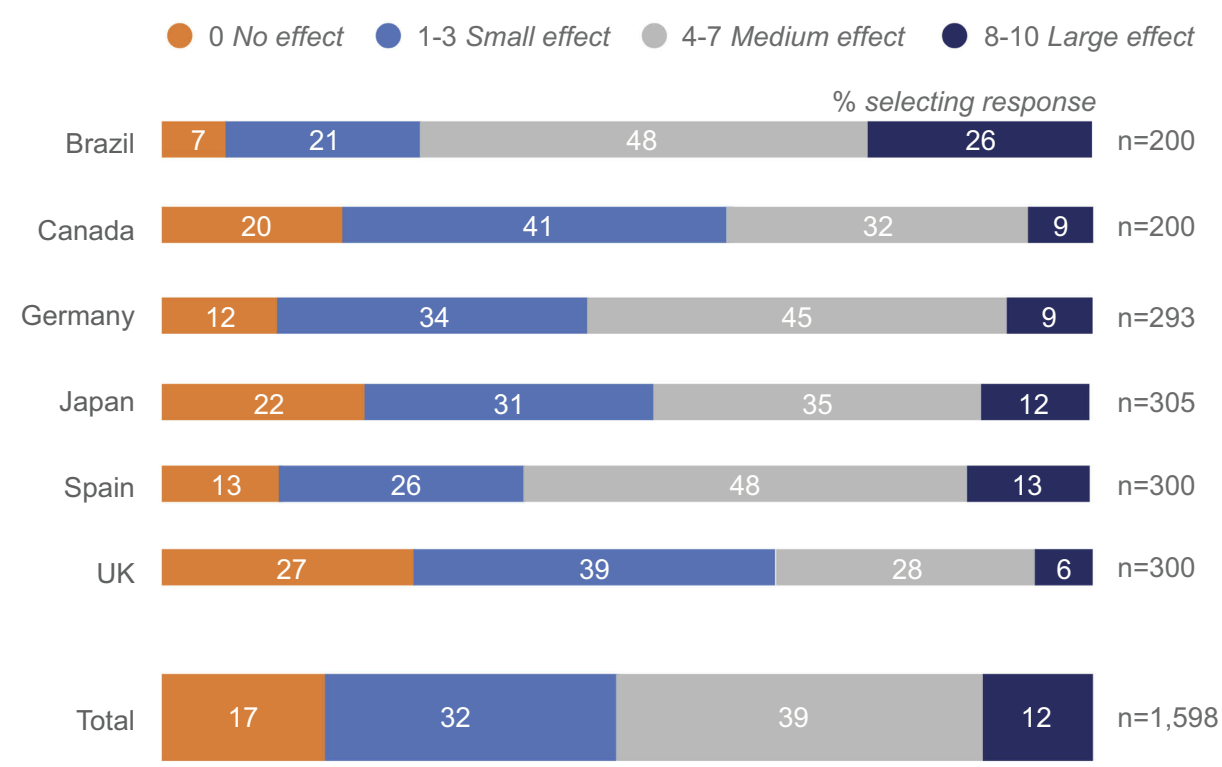

Figure 4 Impact of asthma on regular daily activities other than work. WPAI-SHP Q6: "During the past seven days, how much did asthma affect your ability to do your regular daily activities, other than work at a job?" Answered on a $0-10$ score with $0=$ asthma had no effect on my daily activities and $10=$ asthma completely prevented me from doing my daily activities.

Abbreviations: WPAI-SHP, Work Productivity and Activity Impairment - Specific Health Problem.

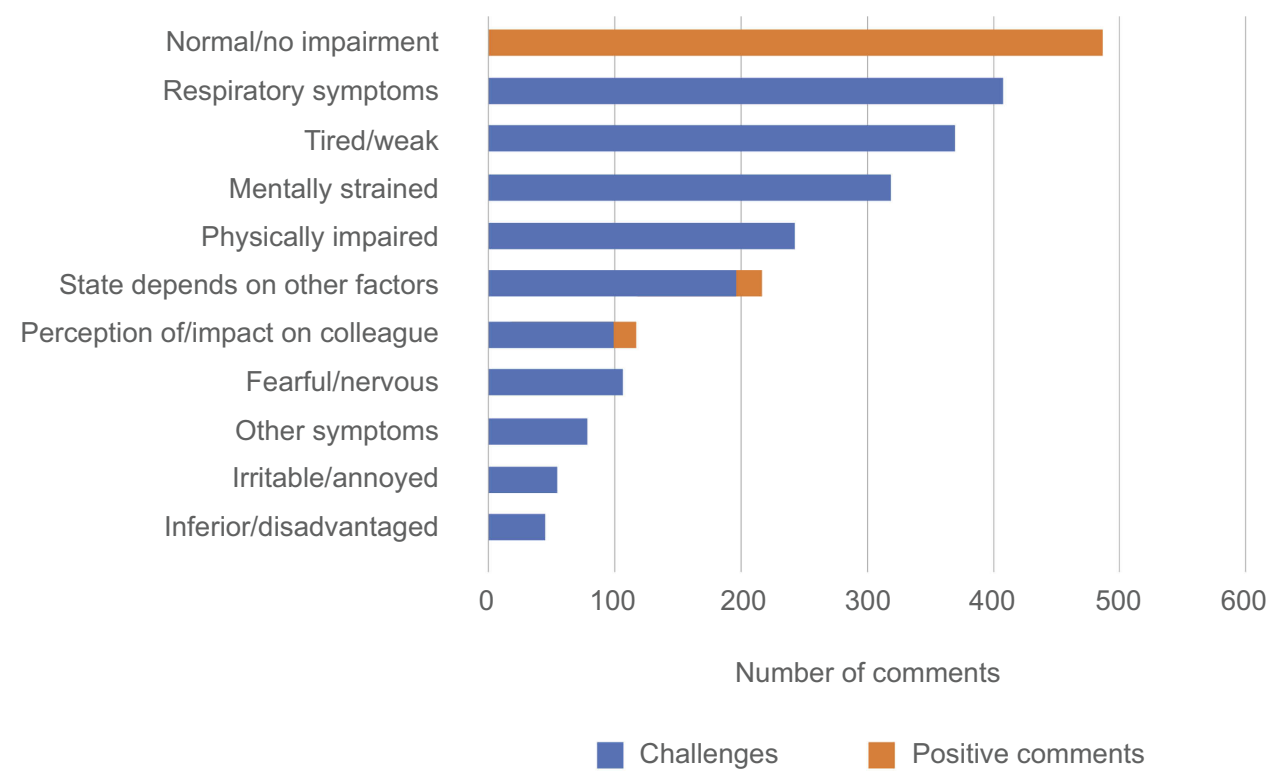

Figure 5 Survey participant comments and perceived challenges encountered at work due to asthma. Additional open-question 7: "How does your asthma at work make you feel?" Overall, I,598 participant responses were recorded from the six countries; each individual could raise more than one challenge.

Further information on the descriptions used by respondents can be seen in Table S1.

\section{Discussion}

Work plays a substantial role in most people's lives, and this study has shown that symptomatic asthma has a large negative impact on a patient's ability to perform with full effectiveness at work. In this multinational survey, both measures of work productivity - absenteeism and presenteeism - were affected by asthma symptoms. In the week leading up to this survey, nearly one-tenth of work time was missed due to asthma, with almost three-quarters of asthma patients reporting a reduction in productivity at work; for $42 \%$ of patients, this was a "prominent" reduction. Comments from the study participants provide multicultural attitudes about disease burden, symptoms and 
employment across a broad age range of patients. They also offer unique personal insights into the emotional well-being of employees with uncontrolled asthma and reveal that challenges faced at work include tiredness, weakness and mental strain, as well as emotional and physical impairment. The findings illustrate that there needs to be further awareness and understanding of the impact of psychological comorbidities associated with uncontrolled asthma.

Wide variation in the impact of asthma on absenteeism and work productivity was observed between the different countries in this survey, which has also been reported previously. ${ }^{7,9,11,25,26}$ Rising disparities in health expenditure between countries may lead certain populations, or entire countries, to appear to have a disproportionately higher asthma morbidity and mortality. This could be a possible explanation for the between-country differences observed in this study. ${ }^{5}$ Brazil, in particular, had a higher percentage of missed working hours and loss in productivity compared with the other countries in this study. This could be because the survey was conducted between April to September, which was after the rainy/humid season in Brazil; higher asthma consultations and hospitalizations have been reported during this season, especially in March, compared with the rest of the year in Brazil. ${ }^{27,28}$ However, more research is needed to establish the reasons for differences between individual countries.

Patients with COPD as well as asthma were found to have a higher mean overall impairment and total work productivity loss than non-COPD patients. For patients aged $\geq 40$ years, mean overall impairment and total work productivity loss both decreased, possibly due to confounding (patients still at work aged 40 years or higher tend to be healthier than the overall patient population of this age group).

Our study has highlighted the negative emotional impact that uncontrolled asthma can have on employees in the workplace and their productivity while at work. A Canadian study with 300 patients with asthma showed that over one-third of patients with asthma had psychological distress (depressive and anxiety symptomatology) as a comorbidity, and this affected both absenteeism and presenteeism. ${ }^{29}$ Furthermore, lack of asthma control significantly correlated with psychological distress, and this was associated with a higher productivity loss compared with patients with controlled asthma and no psychologic distress. ${ }^{29}$ Moreover, a larger study in Finland with over 60,000 employees showed that the risk of long-term permanent work disability is increased in patients with asthma and depression. ${ }^{30} \mathrm{~A}$ recent cohort study with 160,000 participants showed that psychiatric disorders were the largest contributing factor of comorbidity costs to people with asthma, with the greatest economic impact. $^{31}$

This study further contributes to the growing evidence regarding the burden of poorly controlled asthma on patients' lives and the wider society. The 2004 Asthma Insights and Reality global surveys highlighted the international burden of asthma, with absences noted across continents; the percentages of adults who lost working days over a 1 -year period due to asthma were $25 \%$ in the United States, $17 \%$ in Western Europe, $27 \%$ in AsiaPacific, and $23 \%$ in Central and Eastern Europe. ${ }^{18}$ Another recent multinational survey that assessed work productivity in patients with mild asthma (Global Initiative for Asthma Steps 1-2) reported an average of $13.3 \%$ overall work impairment, which included a $12.5 \%$ rise in impairment due to presenteeism. ${ }^{32}$

A recent study from the UK estimated that the cost to society of work productivity impairment due to poor asthma control was $£ 6,172$ million each year. ${ }^{33}$ According to a recent Canadian study, suboptimal asthma control can lead to a projected total discounted societal cost of C $\$ 213.10$ billion for the period 2014-2033. ${ }^{34}$ Another Canadian study also showed that the cost of comorbidities associated with asthma, and subsequent productivity impairment, was approximately C $\$ 1,000$ per week per individual, with high comorbidity versus an asthma patient with no comorbidity. ${ }^{35}$ Uncontrolled asthma and comorbidities can therefore represent a significant resource burden.

Predictors for work absence due to respiratory reasons have been identified, including profession (metal workers and welders are at higher risk compared with office workers), low forced vital capacity, and occupational exposure to vapors, gas, dust/fumes and cleaning products, although it is likely that there are other contributing factors. ${ }^{36-39}$ Whilst our study did not specifically address occupational hazards for employees with asthma, some respondents did mention the unsuitability of their working conditions.

Employers and human resources personnel should work with employees to ensure that their workplace is suitable. An optimal environment may not always be achievable (eg, creating an allergen-free workplace); however, it is important to consider that an employee with severe allergic asthma may require a reduced workload during pollen season in anticipation of reduced 
productivity during these episodes. Short-term contract workers should also be given additional flexibility to work and manage their symptoms with the help of their healthcare professional and employer.

A key point to note is that most of the asthma patients who were screened in this survey had symptomatic asthma despite controller medication. Patients with asthma often accept their symptoms or overestimate how well their asthma is controlled. ${ }^{2}$ There is a need to continue to work with patients to gain better control of their disease.

This current study has many strengths; it utilized validated questionnaires to obtain quantitative and qualitative data from a large patient sample covering multiple countries. This study has provided insights into patients with moderate-to-severe asthma. Despite being an online survey, a wide age range was sampled, demonstrating that it is not just younger generations that respond to online surveys. This study has also re-emphasized the effect asthma can have on a patient's daily activities, with over half of respondents reporting a "prominent" impairment due to asthma on their regular activities.

There were limitations to the approaches used in this study. This was a short Internet-based survey rather than a more in-depth face-to-face or telephone interview, which might have brought out more information from participants and minimized missing data. ${ }^{22}$ The survey was translated for each country, but these translations have not been validated. It also represents only a snapshot from 1 week of the year for each country, and includes some subjective qualitative descriptions as well as quantitative data. It is possible that, due to selection bias, people with socioeconomic, mental or visual impairments may have been excluded. We were not able to validate their asthma diagnosis, symptoms or subjective work productivity. Medication information was based solely on the information provided by the patient and therefore includes some uncertainty. We do not have further characteristics of the people with asthma who were contacted to join the survey but did not respond, while information as to whether patients had undergone education on asthma was also not provided. Furthermore, treatment adherence was not assessed, so lack of control and other outcomes measured may be due to poor adherence. However, previous studies have shown that nearly half of patients with asthma remain uncontrolled despite maximal adherence. ${ }^{40}$

This study highlights the global nature of the problem and the impact asthma has on work. It is vital that the asthma community continues to recognize the need for improved control and more actively assesses how asthma affects quality of life. It is necessary to raise awareness that clinicians should be discussing the impact of asthma on work with their patients. While clinicians tend to ask how asthma impacts a patients' activities and whether their job affects their asthma, it is also important to ask patients how their asthma affects their ability to do their job.

This study contributes to raising awareness of the tangible impact that asthma has, not only on patients, but on companies and the economy. People with asthma often accept their symptoms and the impact that they have on their daily lives. However, clinicians, employers and occupational health teams should be more aware of the impact of asthma on workers and aim to work toward providing support solutions. Workplaces may consider offering education and strategies to support patients in managing their tiredness and physical/mental fatigue in order to help reduce the impact this might have on their productivity and absence. Workplace wellness programs have seen benefits from inviting an asthma educator in to proactively help employees in the workplace. ${ }^{41}$ Interventions that increase adherence to controller therapies have also been shown to be beneficial. ${ }^{42}$

\section{Conclusions}

Time spent at work represents a large part of many people's lives, and this study, through personal insights and quantitative measures, emphasizes the extent to which work time is adversely affected by asthma in patients despite the use of long-term maintenance medication. Around the world, people with asthma report missing work and struggling with work due to their asthma symptoms. Employers and occupational health teams should be more aware of the impact of asthma on workers. Furthermore, it is important for clinicians to ask patients how their asthma affects their ability to do their job and to discuss strategies to help overcome these challenges.

\section{Abbreviations list}

ANOVA, analysis of variance; COPD, chronic obstructive pulmonary disease; WPAI-SHP, Work Productivity and Activity Impairment - Specific Health Problem.

\section{Acknowledgments}

This study was supported by Boehringer Ingelheim International $\mathrm{GmbH}$. The authors would like to thank Katharina Opitz and Valerie Hargreaves for their assistance in the organization and analysis of the survey. 
Kantar Health received funding from Boehringer Ingelheim International $\mathrm{GmbH}$ to conduct the WPAI-SHP survey. Helen Moore, $\mathrm{PhD}$, at MediTech Media provided editorial assistance in the development of the manuscript, funded by Boehringer Ingelheim International $\mathrm{GmbH}$.

\section{Disclosure}

KGJ has spoken on behalf of, and worked as a consultant for, AstraZeneca, Boehringer Ingelheim International $\mathrm{GmbH}$, Chiesi, GlaxoSmithKline, Mundipharma, Napp, Novartis and Pfizer, outside the submitted work. MT has received honoraria from the following companies marketing respiratory and allergy products: Aerocrine, Boehringer Ingelheim International GmbH, GlaxoSmithKline, Merck Sharp \& Dohme, Novartis and Pfizer, outside the submitted work; he is also a member of the BTS/SIGN Asthma guideline steering group and the NICE Asthma Diagnosis and Monitoring guideline development group. MRR reports personal fees from AstraZeneca, Boehringer Ingelheim International $\mathrm{GmbH}$, Chiesi, Menarini, Mundipharma, Novartis, Pfizer, Teva and Bial, and grants and personal fees from GlaxoSmithKline, outside the submitted work. JMF reports being a member of advisory boards for AstraZeneca, Boehringer Ingelheim International GmbH, Novartis, Sanofi-Regeneron, Circassia and Teva; has been paid honoraria for lecturing at symposia organized by these companies; and has also undertaken clinical trials through his employer, the University of British Columbia, for these companies and GlaxoSmithKline. Funding was also provided to the University of British Columbia by Boehringer Ingelheim International GmbH during the conduct of this study. In the last 5 years IP has received speaker's honoraria for speaking at sponsored meetings from AstraZeneca, Boehringer Ingelheim International $\mathrm{GmbH}$, Aerocrine, Almirall, Novartis, Teva, Chiesi and GlaxoSmithKline, and payments for organizing educational events from AstraZeneca and Teva. He has received honoraria for attending advisory panels with Genentech, Regeneron, AstraZeneca, Boehringer Ingelheim International $\mathrm{GmbH}$, GlaxoSmithKline, Novartis, Teva, Merck, Sanofi, Circassia, Chiesi and Knopp. He has received sponsorship to attend international scientific meetings from Boehringer Ingelheim International $\mathrm{GmbH}$, GlaxoSmithKline, AstraZeneca, Teva and Chiesi. He has received a grant from Chiesi to support a phase 2 clinical trial in Oxford. JMH is an employee of Boehringer Ingelheim International $\mathrm{GmbH}$ and $\mathrm{UE}$ is an employee of Boehringer Ingelheim Pharma $\mathrm{GmbH} \& \mathrm{Co}$. $\mathrm{KG}$. CV has spoken on behalf of, and worked as a consultant for, Boehringer Ingelheim International $\mathrm{GmbH}$ and Novartis. The authors report no other conflicts of interest in this work.

\section{References}

1. GBD. 2015 Chronic Respiratory Disease Collaborators. Global, regional, and national deaths, prevalence, disability-adjusted life years, and years lived with disability for chronic obstructive pulmonary disease and asthma, 1990-2015: a systematic analysis for the Global Burden of Disease Study 2015. Lancet Respir Med. 2017;5 (9):691-706. doi:10.1016/S2213-2600(17)30293-X

2. Price D, Fletcher M, van der Molen T. Asthma control and management in 8,000 European patients: the REcognise Asthma and LInk to Symptoms and Experience (REALISE) survey. NPJ Prim Care Respir Med. 2014;24:14009. doi:10.1038/npjpcrm.2014.9

3. Global Initiative for Asthma. GINA report: global strategy for asthma management and prevention. Available from: http://ginasthma.org/ 2018-gina-report-global-strategy-for-asthma-management-and-preven tion/. Accessed October 22, 2018.

4. Ebmeier S, Thayabaran D, Braithwaite I, Bénamara C, Weatherall M, Beasley R. Trends in international asthma mortality: analysis of data from the WHO Mortality Database from 46 countries (1993-2012). Lancet. 2017;390(10098):935-945. doi:10.1016/S0140-6736(17)31448-4

5. Nunes C, Pereira AM, Morais-Almeida M. Asthma costs and social impact. Asthma Res Pract. 2017;3:1. doi:10.1186/s40733-016-0029-3

6. van Schayck OC, Boudewijns EA. COPD and asthma: and asthma: the emergency is clear, now is the time for action. Lancet Respir Med. 2017;5(9):668-669. doi:10.1016/S2213-2600(17)30308-9

7. Fletcher M, Jha A, Dunlop W, et al. Patient reported burden of asthma on resource use and productivity across 11 countries in Europe. Adv Ther. 2015;32(4):370-380. doi:10.1007/s12325-015-0204-6

8. Vietri J, Burslem K, Su J. Poor asthma control among US workers: health-related quality of life, work impairment, and health care use. $J$ Occup Environ Med. 2014;56(4):425-430. doi:10.1097/ JOM.0000000000000123

9. Ojeda P, Sanz de Burgoa V; Coste Asma Study. Costs associated with workdays lost and utilization of health care resources because of asthma in daily clinical practice in Spain. $J$ Investig Allergol Clin Immunol. 2013;23(4):234-241.

10. Wong A, Tavakoli H, Sadatsafavi M, Carlsten C, FitzGerald JM. Asthma control and productivity loss in those with work-related asthma: a population-based study. J Asthma. 2017;54(5):537-542. doi:10.1080/02770903.2016.1220011

11. Sadatsafavi M, Rousseau R, Chen W, Zhang W, Lynd L, FitzGerald JM. The preventable burden of productivity loss due to suboptimal asthma control: a population-based study. Chest. 2014;145(4):787793. doi:10.1378/chest.13-1619

12. Hiles SA, Harvey ES, McDonald VM, et al. Working while unwell: workplace impairment in people with severe asthma. Clin Exp Allergy. 2018;48(6):650-662. doi:10.1111/cea.13153

13. Birnbaum HG, Berger WE, Greenberg PE, et al. Direct and indirect costs of asthma to an employer. J Allergy Clin Immunol. 2002;109 (2):264-270.

14. Cisternas MG, Blanc PD, Yen IH, et al. A comprehensive study of the direct and indirect costs of adult asthma. J Allergy Clin Immunol. 2003;111(6): 1212-1218.

15. Szucs TD, Anderhub H, Rutishauser M. The economic burden of asthma: direct and indirect costs in Switzerland. Eur Respir J. 1999;13(2):281-286.

16. Dean BB, Calimlim BC, Sacco P, Aguilar D, Maykut R, Tinkelman D. Uncontrolled asthma: assessing quality of life and productivity of children and their caregivers using a cross-sectional Internet-based survey. Health Qual Life Outcomes. 2010;8:96. doi:10.1186/14777525-8-96 
17. Schmier JK, Manjunath R, Halpern MT, Jones ML, Thompson K, Diette GB. The impact of inadequately controlled asthma in urban children on quality of life and productivity. Ann Allergy Asthma Immunol. 2007;98(3):245-251. doi:10.1016/S1081-1206(10)60713-2

18. Rabe KF, Adachi M, Lai CK, et al. Worldwide severity and control of asthma in children and adults: the global Asthma Insights and Reality surveys. J Allergy Clin Immunol. 2004;114(1):40-47. doi:10.1016/j. jaci.2004.04.042

19. Sullivan P, Ghushchyan VG, Navaratnam P, et al. School absence and productivity outcomes associated with childhood asthma in the USA. J Asthma. 2017;55(2):161-168. doi:10.1080/02770903.2017. 1313273

20. Pinnock H, Burton C, Campbell S, et al. Clinical implications of the Royal College of Physicians three questions in routine asthma care: a real-life validation study. Prim Care Respir J. 2012;21(3):288-294. doi:10.4104/pcrj.2012.00052

21. Pearson MG BC, editor. Measuring Clinical Outcomes in Asthma: A Patient-Focused Approach. London: Royal College of Physicians; 1999.

22. Reilly MC, Zbrozek AS, Dukes EM. The validity and reproducibility of a work productivity and activity impairment instrument. Pharmacoeconomics. 1993;4(5):353-365. doi:10.2165/00019053199304050-00006

23. Reilly MC WPAI:SHP V2.0. Available from: http://www.reillyassoci ates.net/WPAI SHP.html. Accessed June 19, 2017.

24. Reilly MC WPAI scoring. Available from: http://www.reillyassoci ates.net/WPAI_Scoring.html. Accessed June 7, 2017.

25. Barnett SB, Nurmagambetov TA. Costs of asthma in the United States: 2002-2007. J Allergy Clin Immunol. 2011;127(1):145-152. doi:10.1016/j.jaci.2010.10.020

26. Asthma Australia and National Asthma Council Australia. The hidden cost of asthma 2015. Available from: https://www.nationalasthma.org. $\mathrm{au} /$ living-with-asthma/resources/health-professionals/reports-and-statis tics/the-hidden-cost-of-asthma-2015. Accessed October 24, 2018.

27. Valenca LM, Restivo PC, Nunes MS. Seasonal variations in emergency room visits for asthma attacks in Gama, Brazil. J Bras Pneumol. 2006;32(4):284-289.

28. Silva PR, Rosa AM, Hacon SS, Ignotti E. Hospitalization of children for asthma in the Brazilian Amazon: trend and spatial distribution. $J$ Pediatr (Rio J). 2009;85(6):541-546. doi:10.2223/JPED.1952

29. Moullec G, FitzGerald JM, Rousseau R, Chen W, Sadatsafavi M; Economic Burden of Asthma (EBA) study team. Interaction effect of psychological distress and asthma control on productivity loss? Eur Respir J. 2015;45(6):1557-1565. doi:10.1183/09031936.00141614

30. Hakola R, Kauppi P, Leino T, et al. Persistent asthma, comorbid conditions and the risk of work disability: a prospective cohort study. Allergy. 2011;66(12):1598-1603. doi:10.1111/j.13989995.2011.02729.x
31. Chen W, Lynd LD, FitzGerald JM, et al. Excess medical costs in patients with asthma and the role of comorbidity. Eur Respir J. 2016;48(6):1584-1592. doi:10.1183/13993003.01141-2016

32. Ding B, Small M. Disease burden of mild asthma: findings from a cross-sectional real-world survey. Adv Ther. 2017;34(5):1109-1127. doi:10.1007/s12325-017-0520-0

33. Pavord ID, Mathieson N, Scowcroft A, Pedersini R, Isherwood G, Price D. The impact of poor asthma control among asthma patients treated with inhaled corticosteroids plus long-acting beta2-agonists in the United Kingdom: a cross-sectional analysis. NPJ Prim Care Respir Med. 2017;27(1):17. doi:10.1038/s41533017-0014-1

34. Zafari Z, Sadatsafavi M, Chen W, FitzGerald JM. The projected economic and health burden of sub-optimal asthma control in Canada. Respir Med. 2018;138:7-12. doi:10.1016/j.rmed. 2018.03.018

35. Ehteshami-Afshar S, FitzGerald JM, Carlsten C, et al. The impact of comorbidities on productivity loss in asthma patients. Respir Res. 2016;17(1):106. doi:10.1186/s12931-016-0421-9

36. Alexopoulos EC, Burdorf A. Prognostic factors for respiratory sickness absence and return to work among blue collar workers and office personnel. Occup Environ Med. 2001;58(4):246-252. doi:10.1136/ oem.58.4.246

37. Kim JL, Blanc PD, Villani S, et al. Predictors of respiratory sickness absence: an international population-based study. Am J Ind Med. 2013;56(5):541-549. doi:10.1002/ajim.22178

38. Kim JL, Toren K, Lohman S, et al. Respiratory symptoms and respiratory-related absence from work among health care workers in Sweden. $J$ Asthma. 2013;50(2):174-179. doi:10.3109/ 02770903.2012 .760203

39. Peters J, Pickvance S, Wilford J, Macdonald E, Blank L. Predictors of delayed return to work or job loss with respiratory ill-health: a systematic review. J Occup Rehabil. 2007;17(2):317-326. doi:10.1007/s10926-007-9072-5

40. Bateman ED, Boushey HA, Bousquet J, et al. Can guideline-defined asthma control be achieved? The Gaining Optimal Asthma ControL study. Am J Respir Crit Care Med. 2004;170(8):836-844. doi:10.1164/rccm.200401-033OC

41. MacKinnon NJ, Morais CL, Rose T. Drug-related problems identified in a workplace asthma self-management program. Can Pharm J. 2007;140:110-115. doi:10.1177/171516350714000226

42. Zafari Z, Lynd LD, FitzGerald JM, Sadatsafavi M. Economic and health effect of full adherence to controller therapy in adults with uncontrolled asthma: a simulation study. J Allergy Clin Immunol. 2014;134(4):908-915.e3. doi:10.1016/j.jaci.2014.04.009 


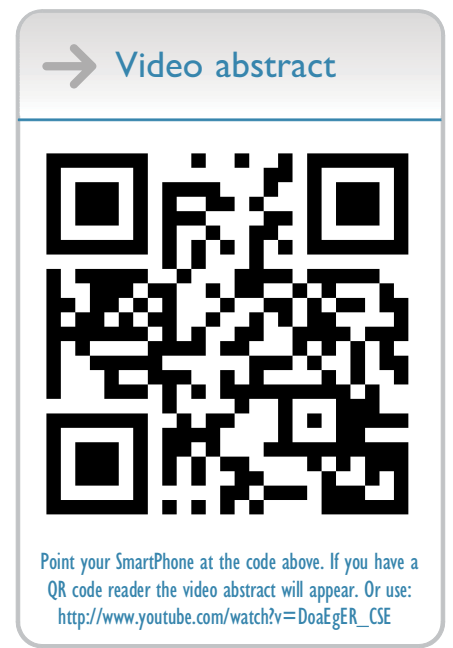

Journal of Asthma and Allergy

\section{Publish your work in this journal}

The Journal of Asthma and Allergy is an international, peer-reviewed open-access journal publishing original research, reports, editorials and commentaries on the following topics: Asthma; Pulmonary physiology; Asthma related clinical health; Clinical immunology and the immunological basis of disease; Pharmacological interventions and new therapies. The manuscript management system is completely online and includes a very quick and fair peer-review system, which is all easy to use. Visit http://www.dovepress.com/testimonials.php to read real quotes from published authors. 